\title{
IMMUNOHISTOCHEMICAL LOCALIZATION OF NotCH SigNALING Molecules in Ameloblastomas
}

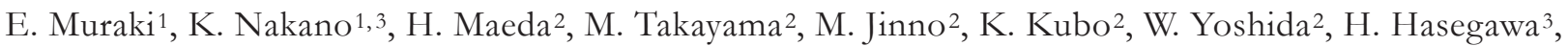 \\ T. Kawakami 1,3 \\ ${ }^{1}$ Hard Tissue Pathology Unit, Matsumoto Dental University Institute for Oral Science, Shiojiri, Japan \\ ${ }^{2}$ Department of Oral Pathology, School of Dentistry, Aichi Gakuin University, Nagoya, Japan \\ ${ }^{3}$ Hard Tissue Pathology Unit, Matsumoto Dental University Graduate School of Oral Medicine, Shiojiri, Japan
}

\begin{abstract}
We examined Notch signaling molecules, Notch1 and Jagged1, in serial large cases of typical solid/multicystic ameloblastoma. In general, Notch positive staining products were frequently detected in the cytoplasms of the cells. In the same cells, Jagged positive staining were also frequently observed, while only occasionally positive in peripheral cells, especially in cuboidal cells. The results showed that these morphogenesis regulation factors are closely related to cytological differentiation in neoplastic cells of ameloblastoma. The Notch and Jagged positive-cell ratios were frequently positive, and the ratios were nearly the same between the varied histopathological, cytological patterns. However, the less-differentiated cells were fewer in number than that of well-differentiated cells.
\end{abstract}

Key words: Ameloblastoma; Notch signaling; Notch; Jagged; Cell differentiation; Immunohistochemistry

\section{INTRODUCTION}

Ameloblastoma is a benign but locally invasive polymorphic neoplasm consisting of proliferating odontogenic epithelium, which usually has a follicular or plexiform pattern lying in a fibrous stromal tissue [1]. There are four basic histopathological variations: 1) solid/ multicystic; 2) extraosseous/peripheral; 3) desmoplastic; and 4) unicystic. Regarding the solid/multicystic type, there are two basic histopathological patterns, the follicular and plexiform. The follicular pattern consists of islands of odontogenic epithelium within the fibrous stromal tissue. The peripheral cells of these islands are columnar, and hyperchromatic, and they are lined up in a palisaded fashion [1]

Notch molecules act as implementation of differentiation, proliferation, and developmental processes. Furthermore, Notch activity causes association with a wide range of developmental disorders of neoplastic cytological differentiation [2-4]. Kumamoto and Ohki [5] have studied Notch signaling molecules using serial cases of ameloblastoma. We have also examined some ameloblastomas [6-10] and other types of odontogenic neoplasms, such as odontogenic myxoma, squamous odontogenic tumor, calcifying cystic odontogenic tumor, and calcifying epithelial odontogenic tumor [11-14]. In our serial examinations, we have no- ticed different features of Notch expression patterns in ameloblastomas, when comparing our data with that of Kumamoto and Ohki [5]. Therefore, in this paper, we re-examined Notch signaling molecules in serial large cases of solid/multicystic ameloblastoma.

\section{MAterials AND METHODs}

The surgical materials of ameloblastoma examined in this study were obtained from operations, and diagnoses were carried out at the Department of Oral Pathology, Aichi Gakuin University School of Dentistry, Nagoya, Japan. We chose a total of 50 cases of ameloblastoma from the recorded surgical files, and the 50 cases were histopathologically re-examined. A total of 40 cases of typical solid/multicystic ameloblastoma [1] were selected. The summarized clinical data of selected 40 cases of surgical material are shown in Table 1. Male 24, female 16; maxilla 4, mandible 36, total 40; and these mean age is 27.6 years old.

Table 1. Summary of Surgical Materials Examined.

\begin{tabular}{clll}
\hline \multicolumn{1}{c}{ Age } & \multicolumn{1}{c}{ Sex } & \multicolumn{2}{c}{ Location } \\
\hline Mean 27.6 & Male 24 & Maxilla & 4 \\
& Female 16 & Mandible 36 \\
\hline
\end{tabular}

Immediately after removal, the surgical materials were fixed in $10 \%$ neutral buffered formalin solution. The specimens were then dehydrated through a series of ethanols, and embedded in paraffin. After sectioning, the series specimens were examined by histopathological (HE) methods.

After histopathological examination, we examined on the distribution of transcription factors of Notch1 and Jagged1 by immunohistochemical (IHC) techniques. IHC examination was carried out using a DAKO EnVision ${ }^{\mathrm{TM}}+\mathrm{Kit}$ (Dako Cytomation, Glostrup, Denmark) with the following 2 antibodies: Notch1 rabbit polyclonal antibody (ab27526, Abcam plc, Cambridge; dilution: $1 / 1000 ; 4^{\circ} \mathrm{C}$, overnight) and Jagged1 rabbit polyclonal antibody (ab7771, Abcam plc, Cambridge; dilution: $1 / 500 ; 4^{\circ} \mathrm{C}$, overnight). As pre-treatment of immunohitochemical staining using 
the above mentioned Kit, autoclave pretreatment $\left(120^{\circ} \mathrm{C}, 10 \mathrm{~min}\right)$ for Notch and protease $\mathrm{K}$ (Room temp, 2 min) for Jagged were applied. Diaminobendizine (DAB) was applied for the visualization of IHC activity and counter staining was carried out by hematoxylin. We included IHC staining using phosphate buffered saline in place of the primary antibody as a negative control.

For the objective rating of the immunohistochemistry, the observation points were divided into the following: 1) peripheral cuboidal cells of nests, 2) peripheral columnar cells of nests, 3 ) central reticular cells of nests, 4) central squamous cells of nests, and 5) stromal fibroblasts. Each case of above-mentioned classification was measured. Those one with positive reaction regardless of dye strength were assumed to be positive. The number of positive cells was totaled, and the ratio of the number of positive cells to the total of the object cells of the strong enlarged image by a light microscope was assumed to be the CS-index. The mean value of -: negative, $0 \%$ cells; + : occasionally positive, less than $25 \%$ cells; ++ : frequently positive, $25 \%-70 \%$ cells; and +++ : almost positive, grater than $70 \%$ cells, was calculated by each CS-index of the cases examined.

The study was approved by the Ethics Committee (Endorsement number \#179, Date: May 29, 2009), School of Dentistry, Aichi Gakuin University.

\section{RESULTS}

Histopathologically, the tumor cell nests of ameloblastoma were proliferated in the stromal fibrous tissues. The growth pattern of these cell nests showed some follicular and some plexiform structures (Fig. 1-A, B, C).

The former consisted of islands of odontogenic epithelium. Typically, the peripheral layered cells of these cell nests were columnar or cuboidal, hyperchromatic, and lined up in a palisade fashion. The peripheral layered cells resembled internal dental epithelium or preameloblasts. The central cells were loosely arranged, showing stellate reticulum. These nests sometimes became cystic formations. Furthermore, the central cells sometimes showed the cytological change of squamous metaplasia.

The latter contains columnar and/or cuboidal cells

Table 2. Rating of CS-index of Notch1 and Jagged1.

\begin{tabular}{lcc}
\hline & Notch1 & Jagged \\
\hline Peripheral cells & & \\
$\quad$ Cuboidal cells & ++ & + \\
$\quad$ Columnar cells & +++ & ++ \\
Central cells & & \\
$\quad$ Reticular cells & ++ & ++ \\
$\quad$ Squamous cells & ++ & ++ \\
Stromal fibroblasts & ++ & + \\
\hline
\end{tabular}

negative, $0 \%$ cells; +: occasionally positive, less than $25 \%$ cells; ++ : frequently positive, $25 \%-70 \%$ cells; +++ : almost positive, greater than $70 \%$ cells arranged in anastomosing strands/cords with inconspicuous stellate reticulum cells.

Through immunohistochemical observation, therefore, we described each case using the following criteria. A summary of the immunohistochemical examination ratings is shown in Table 2.

1) Peripheral cuboidal cells of nests: In general, Notch positive staining products were detected in the cytoplasms of the cells in frequently. In the same cells, Jagged-positive cells were occasionally positive, but less so than Notch-positive cells.

2) Peripheral columnar cells of nests: Notch positive cells were observed in the cytoplasm of most columnar cells, but Jagged was frequently detected in the cells.

3) Central reticular cells of nests: The central reticular cells showed frequently positive to both of Notch and Jagged.

4) Central squamous cells of nests: Both Notchand Jagged-positive cells were frequently detected in the squamous cells, as observed acanthomatous metaplastic cells, but negative and/or not detected in the keratinizing cells.

5) Stromal fibroblasts: Notch positive stromal fibroblasts were frequently scattered in the tissues, but Jagged was occasionally positive, as observed slightly less than Notch.

6) Special findings: Regarding the peripheral cuboidal cells located in the strands and/or cords pattern regions of the follicular nests, both Notch and Jaggeed were mostly negative, but both positive in the peripheral columnar cells of the typical follicular nests (Fig. 1-D, G). On the other hand, both the Notch and Jagged positive stainings were detected frequently in the central area, but Jagged stainings were occasionally positive, slightly less so than Notch in the peripheral layers (Fig. 1-E, H). On occasion, squamous cells, such as acanthomatous cells and keratinizing cells, were observed. The acanthomatous squamous cells showed frequently positive (Fig. 1-F, I), but they were not determined in the keratinizing squamous cells.

\section{Discussion}

Ameloblastoma is one of typical odontogenic benign neoplasm arising from epithelium of the odontogenic apparatus and its remnants. Histopathologically, there are some histopathological variations in the same neoplasm. Heikinheimo et al. (2002), reported the identical genetic and molecular alterations in epithelial odontogenic neoplasms [5], based on data from gene expression in fresh-frozen ameloblastomas and human fetal tooth germs, using a cDNA microarray. Thirtyfour genes exhibited significant changes in expression levels in ameloblastomas. Eleven genes were over-expressed more than three-fold, and 23 genes were under-expressed to below 0.4 of the control level. Some oncogenes were the most over-expressed. SHH gene, TRAF3, CDH12 and 13, TDGF1, and TGF $\beta 1$ were under-expressed. The gene expression profile identifies candidate genes that may be involved in the origination of ameloblastoma and several genes previously unidentified in relation to human tooth development. Therefore, it is necessary to examine the expression 

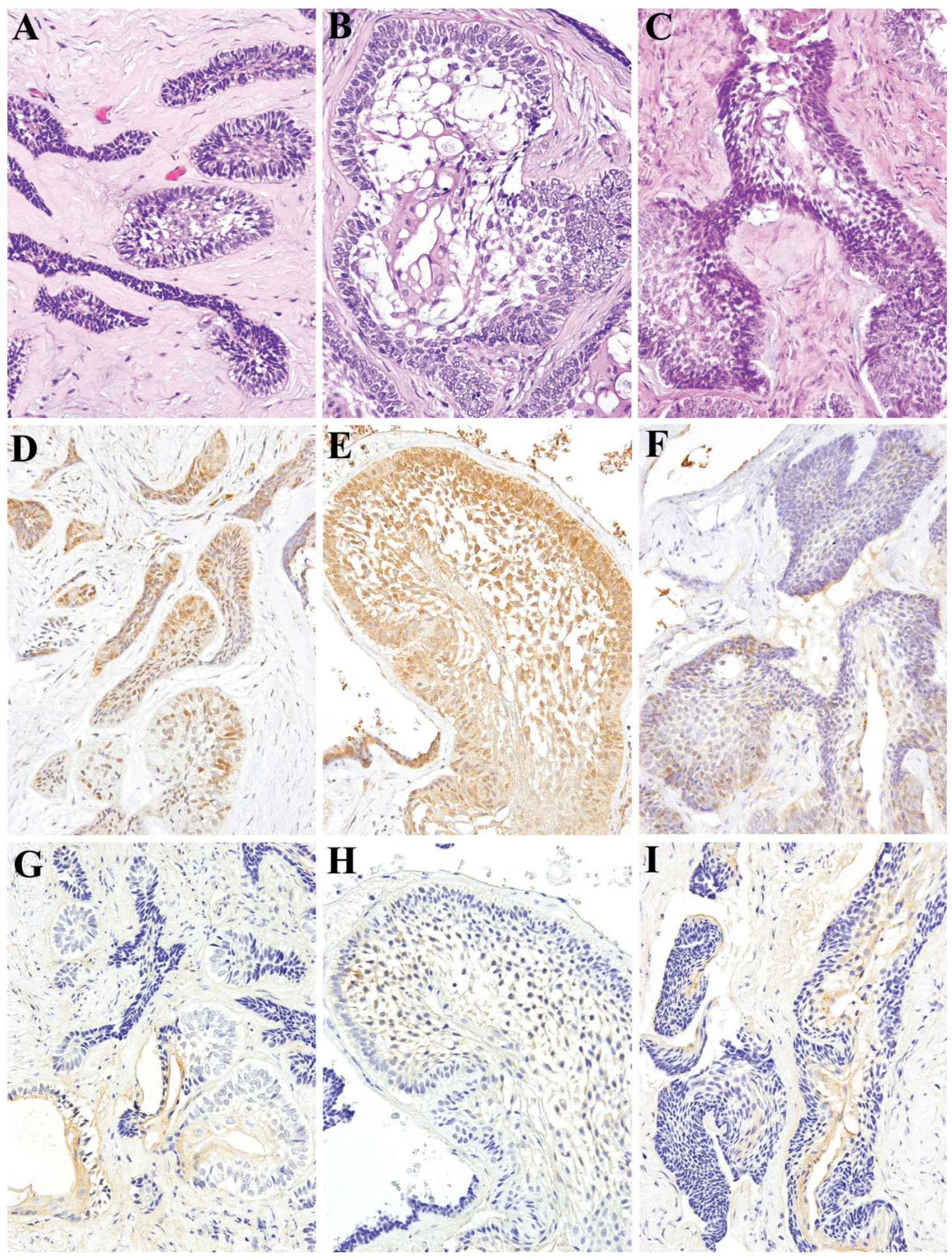

Fig. 1. Histopathological (A,B,C), and immunohistochemical features of Notch1 (D,E,F) and Jagged1 (G,H,I). Magnification X100. A: Case \#20, 21-year-old male, mandible; B, C, F, G, I: Case \#22, 22-year-old, male, mandible; D, E, H: Case \#5, 20year-old male, mandible. 
profiling of the localization in ameloblastomas to compare it with its physiological counterpart, tooth germ.

Previously, we have examined the odontogenic neoplasms and compared then with tooth development regarding regulation factors [6-14], and have published our examination results [6-14] regarding of odontogenic neoplasms, especially for the relation between cytological differentiation in neoplastic cells and their physiological counterparts, tooth germ cells [16-18].

Notch is an evolutionarily-conserved pathway that plays a crucial role in cell fate determination in a variety of tissue types during embryonic developments as well as postnatally $[19,20]$. Notch activity affects the implementation of differentiation, prolifereation, and apoptotic programs to control a broad spectrum of developmental processes, such as neurogenesis, somitogenesis, hematopoiesis, vasculogenesis, keratinocyte growth/differentiation and craniofacial development, including tooth development [2]. In the craniofacial region, mandibular condylar development is one of important features; accordingly, we have examined Notch related factors in this region [21-23]. In neoplastic conditions, such factors are also related to the cell differentiation $[24,25]$. Therefore, we have also examined some odontogenic neoplasms, such as benign and malignant ameloblastoma and its subtypes [6-10], ameloblastic fibroma, odontogenic myxoma [11], squamous odontogenic tumor [12], calcifying cystic odontogenic tumor [13], and calcifying epithelial odontogenic tumor [14]. In the above mentioned published papers, we observed the expression localization of Notch and related molecules. The potential role of Notch signaling is the development and cytological differentiation of odontogenic neoplasms which has gained attention due largely to our above mentioned examination results. Our preliminary findings suggest that Notch1 plays some roles in the cytological differentiation and acquisition of tissue-specific characteristics of neoplastics of neoplastic epithelial cells in these odontogenic epithelial neoplasms [6-10, 12-14], but not in the odontogenic myxoma [11].

Kumamoto and Ohki (2008) looked at Notch signaling molecules in human 9 tooth germ and 32 serial cases of ameloblastoma [5]. In the literature, tooth development is reported to be genetically controlled by regulatory molecules [2]. In mouse molar teeth, expression of Notch1 mRNA has been detected in odontogenic epithelium and has been shown to be transient in inner enamel epithelium at the early bell stage, but to become barely detectable in differentiating ameloblasts [2]. Jagged1 is first expressed in all cells of odontogenic epithelium, and transient upregulation in odontogenic mesenchymal tissues correlates with down regulation of expression in odontogenic epithelium [3]. mRNA expression of Notch1 and Jagged1 were detected in human tooth germs at the initial stage of crown mineralization, and it was concluded that Notch signaling participates in tooth development by regulating the differentiation of odontogenic cells [5].

In the literature [5], ameloblastomas showed expression of Notch1 in central polyhedral neoplastic cells, but not in the keratinizing cells of acanthoma- tous ameloblastomas. Jagged1 was also observed in central cells. Furthermore, Notch1 was also weakly detected in the stromal connective tissues. In comparison with our present results, we obtainly nearly the same results, but there were some differences, especially in the expression localization of squamous cells. As Kumamoto and Ohki showed that the keratinizing cells reacted negative, but our squamous cell showed positive. We think the difference is in the cell stages: the former keratinizing cells showed the final stage of the cells, the ratter squamous cell showed the pre final stage of the cells. In fact, there are positive stainings are detected in the acanthomatous cells in the literature of Kumamoto and Ohki [5].

Furthermore, in the present examination, we detected the localization pattern of neoplastic cells. As observed in the results, Notch1 expression was clearly localized in the cell differentiation sites of the neoplasm. In the periphery of the ameloblastoma cell nests, the expression cell number in the columnar cells was more than that in the cuboidal cells. In the central cells of ameloblastoma cell nests, we thought the expression localization moved to the central area of the nests, according to the differentiation. The features appeared strongly in the Jagged1 expression.

In summary, the results showed that these morphogenesis regulation Notch and related factors are closely related to cytological differentiation in neoplastic cells of ameloblastoma. The Notch and Jagged positive-cell ratio was frequently positive, and was nearly the same between the varied histopathological, cytological patterns; however, the less-differentiated cells were slightly fewer in number that that of well-differentiated cells.

Acknowledgments: This study was supported in part by a Grant-in Aid for Scientific Research (C) (20592349) from the Japan Society for the Promotion of Science and also supported in part by Matsumoto Dental University Promotion Research Grants 2009 and 2010. The authors thank to Professor DM Carlson of Matsumoto Dental University for his critical reading of the manuscript.

\section{REFERENCES}

1. Gardner DG, Heikinheimo K, Shear M, Philipsen HP and Cleman H. Ameloblastomas. In: Barnes L, Eveson JW, Reichart P and Sidransky D (eds) World Health Organization Classification of Tumours: Pathology and genetics of tumours of the head and neck. 2005, IARC Press, Lyon, France 296-300.

2. Mitsiadis TA, Lardelli M, Lendahl U and Thesleff I. Expression of Notch 1, 2 and 3 is regulated by epithelialmesenchymal interactions and retinoic acid in the developing mouse tooth and associated with determination of ameloblast cell fate. J Cell Biol 1995; 130: 407-418.

3. Mitsiadis TA, Henrique D, Thesleff I and Lendahl U. Mouse Serrate-1 (Jagged-1): Expression in the developing tooth is regulated by epithelial-mesenchymal interactions and fibroblast growth factor-4. Develoment 1997; 124: 1473-1483.

4. Mitsiadis TA, Hirsinger E, Lendahl U and Garidis C. Delta-Notch signaling in odontogenesis: Correlation with cytodifferentiation and evidence for feedback regulation. Dev Biol 1998; 204: 420-431. 
5. Kumamoto $\mathrm{H}$ and Ohki K. Detection of Notch signaling molecules in ameloblastomas. J Oral Pathol Med 2008; 37: 228-234.

6. Siar $\mathrm{CH}, \mathrm{Ng} \mathrm{KH}$, Zainal A, Muraki E, Shimizu T, Tsujigiwa $H$, Nagatsuka $H$, Nagai $N$ and Kawakami T. A case report of ameloblastoma of the mandible with examination of Notch signaling. Oral Med Pathol 2006; 11: 35-39.

7. Kawakami T, Nakano K, Siar CH, Shimizu T, Nagstauka $\mathrm{H}$ and Nagai N. Detection of Notch signaling in tooth germ enamel organ-derived neoplastic cells: Immunohistochemical and in situ hybridization examinations. Microsco Microanal 2007; 13: 328-329.

8. Nakano K, Siar CH, Tsujigiwa H, Nagatsuka H, Nagai N and Kawakami T. Notch signaling in benign and malignant ameloblastic neoplasms. Eur J Med Res 2008; 13: 476-480.

9. Siar CH, Nagatsuka H, Chuah KS, Rivera RS, Nakano K, $\mathrm{Ng} \mathrm{KH}$ and Kawakami T. Notch4 overexpression in ameloblatoma correlates with the solid/multicystic phenotype. Oral Surg Oral Med Oral Pathol Oral Radiol En$\operatorname{dod} 2010 ; 110: 224-233$.

10. Siar CH, Nakano K, Han P, Nagatsuka H, Ng KH and Kawakami T. Differential expression of Notch receptors and their ligands in desmoplastic ameloblastoma. J Oral Pathol Med 2010; 39: 552-558.

11. Nakano K, Chelvanayagam P, Born K, Siar CH, Ng KH, Nagatsuka $\mathrm{H}$ and Kawakami T. A study of recurrent giant cell odontogenic myxoma of the mandible with immunohistochemical examination of Notch. Oral Med Pathol 2008; 12: 53-56.

12. Siar CH, Nakno K, Ng KH, Tomida M, Nagatsuka $\mathrm{H}$ and Kawakami T. Squamous odontogenic tumor of the mandibule: A case report demonstrating immunoexpression of Notch1, 3, 4, Jagged1, 2 and Delta1. Eur J Med Res 2010; 154: 180-184.

13. Nakano K, Siar CH, Tomida M, Matsuura S, Tsujigiwa H, Nagastuka $\mathrm{H}$ and Kawakami T. Immunohistochemical observation of Notch signaling in a case of calcifying cystic odontogenic tumor. J Hard Tissue Biol 2010; 19: 147152.

14. Siar CH, Chuah KS, Nakano K, Rivera RS, Tsujigiwa H, Nagatsuka $\mathrm{H}, \mathrm{Ng} \mathrm{KH}$ and Kawakami T. Immunohistochemical study of Notch signaling proteins in the calcicying epithelial odontogenic tumore (Pindborg Tumor). J Hard Tissue Biol 2010; 19: 167-174.

15. Heikinheimo K, Jee KJ, Niini T, Aalto Y, Happonen RP, Leivo I and Knuutila S. Gene expression profiling of ameloblastoma and human tooth germ by means of cDNA microarry. J Dent Res 2002; 81: 525-530.

16. Nakano K, Nagatsuka H, Tsujigiwa H, Gunduz M, Katase N, Siar CH and Kawakami T. Immunohistochemical characteristics of odontogenic neoplasms and their physiological counterparts. J Hard Tissue Biol 2008; 17: 79-90.
17. Kawakami T, Nagatsuka H, Nakano K, Shimizu T, Tsujigiwa $H$, Hasegawa $H$ and Nagai N. Cell differentiation of neoplastic cells originating in the oral and craniofacial regions. In Ivanova LB Ed., Cell Differentiation Research Developments, Chapter 1. Nova Science Publishers, Inc., New York; 2008: 1-30.

18. Kawakami T and Nagatsuka H. Cell differentiation of neoplastic cells originating in the oral and craniofacial regions. Nova Science Publishers, Inc., New York; 2009: 156.

19. Blaumueller CM, Qi H, Zagouras P and ArtavanisTsakonas S. Intracellular cleavage of Notch leads to a heterodimeric receptor on the plasma membrane. Cell 1997; 90: 281-291.

20. Artavanis-Tsakonas S, Rand MD and Lake RJ. Notch signaling: Cell fate control and signal integration in development. Science 1999; 284: 770-776.

21. Shimizu T, Nakano K, Tsujigiwa H, Nagatsuka H, Watanabe T, Okafuji N, Kurihara S, Hasegawa H, Nagai $N$ and Kawakami T. Notch signaling in mandibular condylar cartilage development. Eur J Med Res 2007; 12: 515-519.

22. Shimizu T, Tsujigiwa H, Nagatsuka H, Nakano K, Okafuji N, Kurihara S, Nagai N and Kawakami T. Gene expression of Jagged 2 in mandibular condylar cartilage development. Eur J Med Res 2008; 13: 1-3.

23. Shimizu T, Okafuji N, Nakano K, Kurihara S and Kawakami T. Jagged1 peptide appearing in mandibular condylar cartilage development. Eur J Med Res 2008; 13: 4-6.

24. Zagouras P and Stifani S. Alterations in Notch signaling in neoplastic lesions of the human cervix. Proc Natl Acad Sci USA 1995; 92: 6441-6448.

25. Leong KG and Karsan A. Recent insights into the role of Notch signaling in tumorigenesis. Blood 2006; 107: 22232233.

Received: January 28, 2011 / Accepted: April 13, 2011

Address for correspondence:

Toshiyuki Kawakami, PhD, Professor,

Hard Tissue Pathology Unit,

Matsumoto Dental University

Graduate School of Oral Medicine,

1780 Hirooka-Gobara,

Shiojiri,

399-0781 Japan

Phone: +81-263-51-2035

Fax: +81-263-51-2035

E-mail: kawakami@po.mdu.ac.jp 